\title{
Examining family language policy through realist social theory
}

\author{
S E Y E D H A D I M I R V A H E D I \\ University of Oslo, Norway
}

\section{A B S T R A C T}

In this article, I argue that one social theory that could help us better understand the interaction between social structure and human agency in the context of family language policy (FLP) research is realist social theory. FLP studies in multilingual contexts have shown that home often becomes a site where dominant societal ideologies and discourses of structuring nature compete with individual views and agency, ultimately informing language behavior. Realist social theory advocates the analytical separation of structure and agency and attributes causal powers to both social structures and individual agency. This conceptualization of structure and agency prevents us from falling into structural determinism or individual voluntarism. Through examining the linguistic ideologies and practices of thirteen mothers of young children in Tabriz, Iran, I illustrate how family language policy emerges in interaction with and response to structural powers. (Family language policy, realist social theory, Iranian Azerbaijanis, agency, social structures, language maintenance)

\section{N T R O D U C T I O N}

Language policy and planning (LPP) scholarship has moved away from considering policy as exclusively one of the affairs of states to focusing on how a socially situated approach to language policy analysis could offer insightful information on the individual's role in policy interpretation and appropriation in various domains and institutions below the state-level, and how this ultimately leads to the transformation or reproduction of certain social structures (Tollefson 1991, 2006; Hult 2010, 2017a; Johnson 2013; Lane 2015; Skerrett 2016). As an offshoot of this shift to examining language policies at a micro level, a burgeoning area of research within LPP, namely family language policy (FLP), has evolved over the past two decades to shed light on what family members believe about particular languages, what they actually do with languages they know, and what efforts they make to maintain/alter the linguistic status quo within the family (Spolsky 2004, 2009).

While the primary focus of FLP research has been on the dynamics of language ideologies and language socialization inside the home and its impact on child 
language acquisition (Lanza 1998, 2007; De Houwer 1999; Gafaranga 2010; Kheirkhah \& Cekaite 2015, 2018; Smith-Christmas 2016; Fogle \& King 2017), FLP scholars have also acknowledged the relevance and the impact of familyexternal sociopolitical and economic forces on parents' and children's language ideologies and practices. This 'porosity' of the domain of home with respect to external forces (Canagarajah 2008:171; Van Mensel 2018:238) makes it worth investigating how the private and public sphere of social life and the accompanying requirements of each - that is, orientations towards intimacy and family-bound affection, and orientations towards trajectories of success and mobility, respectively—intersect and compete at home (Curdt-Christiansen 2013; Mirvahedi \& Macalister 2017; Haque 2019). In Blommaert's (2019:3) words, FLP research can unravel a 'cross-scalar complexity' which is 'a stratified and polycentric language-ideological construction enveloping multiple resources and scripts for their deployment across scales'. The polycentricity and stratified nature of family language policy arguably entails that the interplay between different social strata and scales be systematically investigated to understand how individual agency interacts with social structure, and what is exactly meant when the structure - agency relationship is invoked.

This is where, as I argue here, Archer's (1995, 2000, 2003, 2007, 2012) realist social theory finds its rationale and legitimacy in FLP research. Realist social theory advocates an analytical separation of structure and agency that would allow the co-occurrence of the examination of the dynamics of FLP at home and the sociopolitical structures outside the home in a single body of research. This will arguably help us better understand how certain power relations and subjectivities are (re)produced or resisted by discursive, ideological, and other social practices that in turn produce real effects (Sealey 2007). Applying realist social theory to the case of family language policy in Tabriz, Iran, I illustrate that realist social theory as an underlying social theory for FLP studies could offer fresh insights into how FLP emerges out of the interaction between individual agency and social structures.

\section{RE A L IS T S O C I A L THEOR Y}

Realist social theory has emerged as a response to studying the interplay between structure and agency that ends up in an analytical conflation of the two-either upward (conflating structure within agency), downward (conflating agency within structure), or central (agency and culture mutually conditioning one another, as in Giddens' structuration theory). Social realism thus dismisses the assumption that the key to understanding social systems is individual because overprivileging individual agency as free and rational will make it difficult to account for the persistence of social problems such as inequalities and discriminations. Any inclination towards the absolute power of structure over individual is also considered problematic because such a view challenges us to explain social change by people (Sewell 1992; Hays 1994; Carter \& Sealey 2000; Sealey \& Carter 2004). Finally, Giddens' (1979) structuration theory, which argues that structure and 
agency are mutually constitutive (both are the two sides of the same coin), is not viewed as a viable explanation because it compacts them into 'one indistinguishable amalgam', thus precluding scrutiny of their interplay over time (Willmott 2002:7).

In avoiding conflations of any sort, realist social theory equips the researcher with a number of theoretical and conceptual understandings. First, it takes an ontological position with respect to realism, and defines it as the belief that the world in which individuals live exists and extends beyond them, independently of what they think about it (Elder-Vass 2014). The consensus among social realists is that the social realm is made up of both discursive and material (nondiscursive) elements and their respective distinct and emergent properties. What helps resolve the structure-agency problem here is to recognize that the social world made of discursive and nondiscursive realities is 'SUI GENERIS real because it is not temporally coterminous with its creators' (Willmott 2002:12, emphasis in original). Thus, agency is seen in this light as involving 'a temporally embedded process of social engagement', which is 'informed by the past' but also 'oriented toward the future (as a 'projective' capacity to imagine alternative possibilities) and toward the present (as a 'practical-evaluative' capacity to contextualize past habits and future projects within the contingencies of the moment)' (Emirbayer \& Mische 1998:962).

This reflexive capacity of individuals to evaluate past and present influences and forces and come up with a plan for the future rules out a view of individuals as merely 'cultural dopes' and 'bearers of a mode of reproduction' (Giddens 1979:71) or as 'rational' and 'free' beings in their choice (Sewell 1992). Rather, acting within sets of structural possibilities and limits in the real world within certain parameters (Bouchard 2017:78), human beings have the power to deliberate upon such structural constraints and enablements and act creatively, which could either reproduce or transform the status quo (Archer 2000, 2003, 2007, 2012; Bouchard 2017).

In conceptualizing agency and structure as both having real, distinct, and emergent properties that are irreducible to one another, sociological realism views the social world as stratified. While in many studies, social strata have referred to social classes, castes, and levels, each with their own access to resources and privileges, society or the adjective social in social realism is understood as an entity composed of multiple layers or strata, with three core social strata being agency, structure, and culture (Bouchard \& Glasgow 2018). Structure and its emergent properties are distinguished by 'their primary dependence on material resources (physical and human)', whereas the stratum of culture and its emergent properties are identified by their reliance on 'cultural and ideational resources' (Carter 2000:93). This means that people in their deliberations upon their projects encounter both the structural and cultural (ideational and normative recourses) constraints and enablements that can systematically and powerfully influence human practices because they guide a person's attitudes, perceptions, and motivations (Edwards 2016). However, as noted above, in sociological realism, this does not mean they have absolute power and influence over individuals; such an effect is not realized 
unless the human agents activate the causal powers of an objective structural property (Archer 2007).

Grounding FLP research within sociological realism allows us to argue that although family language policy is ultimately 'SELF-induced and SELF-policed' (Blommaert 2019:5, emphasis added), it emerges in interaction with and in response to structural and cultural affordances and constraints. This contributes to our understanding of structural and cultural powers and how parents and children mobilize them, which ultimately shapes their linguistic ideologies and practices at home. As such, while acknowledging structural and cultural forces, family members' agency is neither over nor under privileged in the analysis.

In the following sections, I demonstrate how applying realist social theory to FLP studies can provide us with fresh insights into how FLP is shaped. After presenting the methodology, I depict the structural affordances and constraints Azerbaijanis in Iran encounter in their daily life. Then I illustrate how parents' views of linguistic issues in the home are affected and shaped in response to the social structures that ultimately define FLP in their homes.

\section{METH O D O L G Y}

\section{Research design}

Two accounts are presented in this article. First, an account is presented of the sociopolitical, historical, economic, and discursive structures, each with their own enablements and constraints, in which Iranian Azerbaijanis have lived. The data for this section are drawn from a systematic literature review and qualitative metaanalysis of the findings of previous studies conducted on the community.

The second account comes from a qualitative inquiry, including a theoretical thematic analysis of semistructured interviews with parents of young children from different walks of life. Considering thematic analysis as a qualitative method for identifying, analyzing, and reporting patterns (themes) within data, Braun \& Clarke (2006:82) explain that 'a theme captures something important about the data in relation to the research question, and represents some level of patterned response or meaning within the data set'. Moreover, Braun \& Clarke distinguish between the inductive/bottom-up thematic analysis and the theoretical/deductive thematic analysis. While in the former, coding the data is done "without trying to fit it into a pre-existing coding frame, or the researcher's analytic preconceptions' (making it similar to Grounded Theory), theoretical/deductive thematic analysis is conducted based on 'the researcher's theoretical or analytic interest in the area, and is thus more explicitly analyst driven' (Braun \& Clarke 2006:83). Given that the current study is based on realist social theory, a theoretical thematic analysis has been used as a useful qualitative method. Although coding in both thematic analyses is always an 'idiosyncratic' and 'interpretative practice', and it reveals a great deal about the researcher's 'ontological and epistemological beliefs' (Hadley 
2017:103), this can become a particularly serious pitfall in theoretical thematic analysis in which the analysis is done based on a pre-existing theoretical framework. Thus, following Hadley (2017), deliberate efforts have been made to both 'externalize and suspend' any beliefs stemming from the theoretical stance of the study to make coding 'as descriptive and non-judgmental as possible' (Hadley 2017:103).

\section{Procedure}

The participants were selected through purposeful convenience sampling from different walks of life with varying socioeconomic standings in the society. Therefore, parents with different educational and occupational backgrounds and from different neighborhoods of residence were recruited, which yielded a fairer representation of the Azerbaijani population in Tabriz (see Table 1). They were then interviewed individually in the Azerbaijani language about their linguistic ideologies and practices with respect to the maintenance of Azerbaijani and learning Persian in the family and society, as well as the reasons for each decision and practice they exercise in the family (a total of approximately seven hours of interviews). Extracts from the interviews in this article were translated into English. From a realist social perspective, interviews serve as a means to listen to the subjects' internal reflexive deliberations with respect to different issues, that is, individual discourses. Examining these internal conversations that are spoken out loud in the interviews illuminates how the individuals position themselves against the constraints and affordances the social structures bestow upon them.

\section{Analytical tool}

Three out of four coding phases proposed by Charmaz (2006), that is, initial, focused, and axial, were applied to the collected data to minimally organize it in rich detail (see Braun \& Clarke 2006:79). In the initial phase, the data were read line by line and each segment of the data was given a name. No pre-existing categories from realist social theory were applied to the data at this state. This ensured remaining open, staying close to the data, and preserving actions, the principles that Charmaz (2006:49) deems necessary for initial coding. Then, in the focused coding, the most significant and/or frequent initial codes were sorted, synthesized, integrated, and organized into larger segments. This required decisions about 'which initial codes make the most analytic sense to categorize your data incisively and completely' (Charmaz 2006:57). The decisions in the present study were informed by theoretical insights proposed by the realist social theory above. Thus, the codes were organized in line with structural forces that influence the parents' agency in the home, that is, either constrain or afford possibilities for better language maintenance.

In the third phase, axial coding, the properties and dimensions of each category were specified, and related categories and subcategories were connected; this gave 
TABLE 1. Participants' demographic information.

\begin{tabular}{|c|c|c|c|c|c|c|}
\hline Participants & Parent's education/occupation & L1 & $\mathrm{L} 2$ & Number of children & Gender of the children & Place of residence \\
\hline $\mathrm{P} 1$ & $\mathrm{PhD}$, dentist & Azerbaijani & Persian & 2 & male & Shahrak-e-Yaghchian \\
\hline $\mathrm{P} 2$ & $\mathrm{PhD}$ in Persian literature, lecturer & Azerbaijani & Persian & 1 & male & El-Gholi \\
\hline P3 & MA, homemaker & Azerbaijani & Persian & 1 & male & El-Gholi \\
\hline $\mathrm{P} 4$ & $\mathrm{PhD}$ in chemistry, homemaker & Azerbaijani & Persian & 1 & male & El-Gholi \\
\hline P5 & Associate degree in sports management, homemaker & Azerbaijani & Persian & 1 & male & El-Gholi \\
\hline P6 & Diploma, homemaker & Azerbaijani & Persian & 2 & male & Laleh Square \\
\hline P7 & Diploma, homemaker & Azerbaijani & Persian & 1 & male & Laleh Square \\
\hline P8 & Diploma, homemaker & Azerbaijani & Persian & 1 & male & Laleh Square \\
\hline P9 & MA, homemaker & Azerbaijani & Persian & 1 & male & Shahrak-e-Parvaz \\
\hline P10 & Diploma, homemaker & Azerbaijani & Persian & 2 & male & Laleh \\
\hline P11 & Diploma, homemaker & Azerbaijani & Persian & 2 & male/female & Laleh \\
\hline P12 & Diploma, homemaker & Azerbaijani & Persian & 2 & male/female & Shahrak-e-Andisheh \\
\hline $\mathrm{P} 13$ & Primary school, homemaker & Azerbaijani & Persian & 2 & male/female & Laleh \\
\hline
\end{tabular}


coherence to the data, fractured during the initial coding, and thus to the emerging analysis (Charmaz 2006:60). The analysis of the initial categories in terms of their properties and dimensions and mapping them onto the theoretical insights from realist social theory resulted in discarding some of the categories.

The final phase, theoretical coding, proposed by Charmaz (2006), was not done in this study. In Grounded Theory, theoretical coding is carried out within inductive thematic analysis to integrate the themes into a theory. Having based the present study on realist social theory and having applied deductive/theoretical thematic analysis to the data makes the fourth phase of coding redundant.

\section{A N A L Y S IS}

\section{Iranian Azerbaijanis: Structural enablement and constraints}

Contemporary Iran with a population of just over eighty million is home to a variety of Indo-European as well as Turkic languages. Although there is no exact census about the number of speakers of different languages, it is commonly agreed that Persian (Farsi) speakers account for just over half of the total population. Azerbaijani speakers stand second with a population between sixteen percent (see HaddadianMoghaddam \& Meylaerts 2015) to twenty-four percent (see Bani-Shoraka 2009) of the population. Other ethnic groups are Gilaki and Mazandarani (eight percent), Kurd (seven percent), Arab (three percent), Lur (two percent), Baluch (two percent), and Turkmen (two percent) (Tohidi 2009).

Notwithstanding the noticeable size of the Azerbaijani-speaking population in Iran, the language has always been overshadowed by Persian. Since the Constitutional Revolution in 1905-1906, Persian has functioned as the only official and national language of the country (see Spooner 2012; Haddadian-Moghaddam \& Meylaerts 2015). Since then, any type of language activism has been overtly and covertly suppressed by the central governments (see Hayati \& Mashhadi 2010). Today, however, two key Constitutional Articles, 15 and 19, clearly recognize ethnic minority communities' rights to some institutional supports and does not allow any discrimination on the basis of race, ethnicity, and language.

\footnotetext{
ARTiCle 15

The official language and script of Iran, the lingua franca of its people, is Persian. Official documents, correspondence, and texts, as well as textbooks, must be in this language and script. However, the use of regional and tribal languages in the press and mass media, as well as for teaching of their literature in schools, is allowed in addition to Persian.

ARTICLE 19

All people of Iran, whatever the ethnic group or tribe to which they belong, enjoy equal rights; and color, race, language, and the like, do not bestow any privilege.
}

These constitutional articles legitimate provision of institutional support to speakers of minority languages (labeled as regional and tribal languages) and disapprove of any discrimination based on race, language, and color. Yet, the greatest emphasis has been placed upon Persian by specifying it as the only official language 
of the country. In spite of not specifying the language of instruction in schools, specific attention to writing in Persian in official domains and institutions, for example, schools and administrative contexts, suggests that education must be through the medium of Persian (Sheyholislami 2012). Persian is thus implicitly treated as the 'ideal' language for education and socioeconomic development (see Phillipson 1988:341-42) for all Iranians regardless of their ethnicities.

Moreover, the merely 'permissive' (Fishman 2013:479) tone of Article 15, without making any reference to any compelling provisions about teaching nonPersian languages as a subject or as a medium of instruction within a bilingual education scheme, and using these languages in administration and public services, leaves the fate of the minority languages to market forces. These 'no-policy policy' situations, as Fishman (2006) argues, tend to work in favor of the dominant languages. As a result, non-Persian languages such as Azerbaijani have been restricted to informal domains (Bani-Shoraka 2009).

Similar to Article 15, Article 19 provides a framework for protecting human and linguistic rights based on the assertion that in Islam, and thus in the Islamic Republic of Iran, 'the question of border, colour, language and race doesn't exist' (Paul 1999:209). Nevertheless, no language planning to protect and promote linguistic rights of ethnic minorities has been conducted, leaving these Articles of the Constitution inert (Hassanpour, Sheyholislami, \& Skutnabb-Kangas 2012). What has consequently ensued is that the ethnic groups who do not speak Persian as their mother tongue have had to become bilingual (Haddadian-Moghaddam \& Meylaerts 2015). This is by no means to suggest that bilingualism is a sinister phenomenon per se; however, given the circumstances for ethnic minority communities in Iran, bilingualism among these groups does not seem to be stable (Fishman 1972), increasingly turning into monolingualism in Persian across ethnic minority communities.

Historically, Iranian Azerbaijanis have faced unfavorable circumstances over the last century. As Hayati \& Mashhadi (2010) report, since the Qajar dynasty (17791925), the state policy with respect to minority languages has been of a coercive and suppressive nature, trying to assimilate them into the mainstream Persian language and culture. The Azerbaijani accent, for example, has been the butt of jokes throughout the country during the Pahlavi dynasty (1925-1979). The saying Turk-e-Khar 'donkey Turk' and many other racist jokes along with negative representation of Azerbaijanis in the media have been leveled at Azerbaijanis, denying the minority community its humanity (Shaffer 2002; Asgharzadeh 2007:148). Although such negative representations of Azerbaijanis in jokes and the media have diminished since the Islamic Revolution in 1979, recent research suggests that the negative impact of these jokes and ridicules still continues to influence people's attitudes and perceptions. For example, Naghdipour (2014) and Karimzad (2018) argue that the increasing reproduction of ethnic jokes or other cultural productions about an ethnic group can inevitably construct social 'realities', which can be transferred to 'nonjocular' contexts as well. Using a matched-guise technique, Mirshahidi (2017) also shows how native Persian speakers associate speaking 
Persian with an Azerbaijani accent with negative attributes such as distrust, dishonesty, and insincerity.

It was not until 2000 that the situation of minority groups in Iran began to gradually improve. With the prevalence of satellite dishes and people's increasing access to satellite channels at very little cost, the government decided to establish local provincial TV channels for minority groups. Metaphorically speaking, the government intended to kill two birds with one stone, both to compete with the influence of the media broadcast from other countries and to provide a sort of institutional support for the minorities. Thus, Sahand TV, a local TV channel for Azerbaijanis, was established in Tabriz in 2000. Since its establishment, the channel has allocated its airtime equally to broadcasting programs in Persian and Azerbaijani, which, as Sepehri (2010) writes, is mandated by an executive order issued by the Islamic Republic of Iran Broadcasting (IRIB) in the case of local TV channels and radio stations. As a result of not being a fully fledged minority channel and for other reasons, such as low-quality unattractive programs broadcast in Azerbaijani, the channel has not been able to fully function as an influential institutional support for the Azerbaijani-speaking community. The channel today stands as one of the least popular channels with Azerbaijanis. Research shows that only one percent of the audience residing in Tabriz watches Sahand TV. Most Azerbaijanis prefer to watch Persian channels, broadcast from inside and outside the country, and Turkish channels, broadcast from Turkey, instead (Mirvahedi \& Nasjian 2010; Mirvahedi 2012, 2017; Zeinalabedini 2014).

Although some of the minority languages are present in the media today, they have never been allowed in the education system. This monolingual approach in the centralized education system of Iran has been known as a 'sink or swim' form of education (May 2012:172). This means that non-Persian speakers entering the education system either learn Persian very quickly or risk doing badly at school. The case of Azerbaijani is particularly noteworthy because it has a very rich literary tradition, and a few publications in the language are released every year (Riaux 2008). In spite of this, the Azerbaijani language has been excluded from the educational domains.

The erasure of the language from the education system and its influence on Azerbaijanis' use of the language in writing is clearly reflected in the linguistic landscape of traditionally Azerbaijani communities. For instance, Mirvahedi (2016) found that the Azerbaijani language is absent from public signage erected both by governmental bodies and the private sector in the city of Tabriz. Persian-only and/or Persian-English bilingual signs are the default in public areas. The marginalization of Azerbaijani in any domains where literacy and writing are required has consequently reduced it to an aural/oral language.

Language policies of this kind have not been without their impact on Azerbaijani-speaking families. Despite the Azerbaijani speakers' general positive attitudes towards their language (Rezaei, Latifi, \& Nematzadeh 2017), traces of gradual language shift to Persian in families have been observed (Mirhosseini \& 
Abazari 2016). As Mirhosseini \& Abazari's (2016) study shows, only about half of their participants consider it valuable to have Azerbaijani offered in the education system. Approximately twenty-five percent of them believe that Azerbaijani cannot help them succeed and make them proud. What ensues as a corollary to such attitudes is that families speak Persian with the children at home to ease their integration into the schooling system.

Notwithstanding these constraining pressures on Azerbaijanis in Iran, they have managed to maintain their ethnic language. What provides them with the possibilities to still counter the imposed language regime and maintain their language, at least as an aural/oral language, is the demographic and historical structure and the economic, social, and cultural capital that goes with it. Azerbaijani-speaking communities are concentrated in Northwest cities and towns in Iran, with their language spoken as the main language of interaction in families and cities. This socalled 'demographic agency' (Sealey \& Carter 2004:11) gives the community enough room to maneuver with respect to maintaining its language. Domains and institutions less regulated by official language policies and regulations, for example, workplaces, mosques (the domain of religion), and home, provide Azerbaijanis with space to actively use and maintain their language. However, as mentioned above, the Azerbaijani language is being overwhelmed in many formal domains and institutions, which is increasingly leading to Azerbaijani language attrition among the children (see Hawes \& Mirvahedi 2013).

What I have shown so far are the structural constraints and affordances that the Azerbaijani community in Tabriz encounters. In the following section I present a report of the findings of semistructured interviews with thirteen mothers of young children from upper, middle, and lower socioeconomic classes. The parents' accounts of their linguistic ideologies and practices illustrate how the social structures depicted above are not merely 'background information' (Williams 1992:66). Rather each and every piece of reality with its own causal power contributes to the emergence of a certain type of family language policy in the home.

\section{Family language policy: Parents' agentive roles}

Four main themes emerged from the analysis of the data, showing the interplay between structural influences in shaping family members' agency at home: (i) Persian as the only official language and lingua franca of the country, (ii) lack of institutional support for Azerbaijani, (iii) historical stigmatization of Azerbaijani-speaking Turks, and (iv) limited resistance to the existing structure.

\section{Persian as the only official language and lingua franca of the country}

Language rules, regulations, and laws are considered to be amongst the most effective and powerful mechanisms in democratic societies to turn ideologies into practices. Such officiality ultimately influences 'the personal freedom of 
individuals and groups', imposing and perpetuating a certain language behavior both in private domains and the public sphere (Shohamy 2006:60). The parents' remarks below highlight how the official and national status of Persian in Iran informs their practices within their family.

P2: I spoke with my child in Azerbaijani up to about 2 years since his birth. But when he was about 2, I began speaking Persian with him. I liked him to be a Persian-speaker ... I thought new languages can enhance the mental capacities of the children and I've observed that. Now my child, compared to others, speaks Persian much better and more clearly and expresses his feelings more comfortably. The official language of the country is Persian. I believe the more he can manage himself in Persian, the better. He can communicate without any challenges with people who speak Persian here and there, among the relatives. And certainly, it will be very beneficial for him at school.

The parent (P2) who holds a PhD degree in Persian literature expresses her willingness and decision to raise her son as a Persian-speaker. Believing that "new languages can enhance the mental capacities of the children" and taking his son's ability to "speak Persian much better and more clearly and express his feelings more comfortably" as a sign of enhanced mental capacity, she justifies why she has spoken Persian with her son since he was two. Further, reflecting upon her decision to invest in her son's competence in Persian, she links exercising her active agency to bring up her son in Persian to the official status of Persian in the country, and how "it will be very beneficial for him at school". Because declaring a given language as the official and national language implies and entails granting higher status and functions to that language, it perpetuates the power and hegemony of the language and its speakers, and leads to the marginalization of others (Shohamy 2006:65). Having functioned as the only official language over the last century, Persian has become the only lingua franca in Iran, further persuading the parents to invest in Persian. The lingua franca status of Persian and its impact on the parents' agency is reflected in the parents' remarks.

P5: If my official language was Azerbaijani, the whole country would speak Azerbaijani. Unfortunately, we live in a country that we have to know Persian.

P12: Our country is mostly Persian speaking, so if they [the children] go somewhere they have to have mastery of Persian too.

P11: Persian speakers are more comfortable in Iran. Even if they come to Azerbaijani speaking cities, they will have no problems because Azerbaijanis learn Persian in schools.

P12, with a diploma degree, is a mother of two children and a homemaker. Viewing Iran as "mostly Persian speaking", she argues that her children "have to have mastery of Persian", especially "if they go somewhere". Despite the fact that Iran is a multilingual country in which more than sixty languages and dialects are spoken, Iran is seen as mostly Persian-speaking in this parent's eyes. This is arguably because of the fact that Persian has been institutionalized as a lingua franca of the country over many years, now manifesting itself as the 'public representation of the nation-state' in individuals' discourse (Shohamy 2006:65). Minorities having mastery of this lingua franca will thus grant them the same privileges that native speakers are thought to possess. The least of these privileges, as put by P11, 
is feeling "more comfortable" and "having no problem" when Persian speakers travel to different parts of the country, even to the areas in which ethnic minorities predominantly live, because the minorities such as Azerbaijanis "learn Persian in schools". It is such a reward system (Fishman 2006) sanctioned by the official and national status of Persian that needs to be considered to be a structural force affecting the parents' agency at home, encouraging them to promote Persian in the family.

\section{Lack of institutional support for Azerbaijani}

Institutional support is considered to be one of the most influential factors contributing to the vitality of ethnolinguistic groups in assisting them to remain a distinctive and active collective entity in intergroup communications (Giles, Bourhis, \& Taylor 1977). The second theme emerging from the data, which was closely linked to the first theme, demonstrates how the lack of fully fledged institutional support for Azerbaijani, in particular supportive and promotive educational policies and media, shapes the parents' linguistic behavior at home.

P6: I started talking to my child in Persian when he was 6 months old ... The reason for my choosing Persian is that my older son had many problems at school. He could explain everything in Azerbaijani but not in Persian. He would confuse and mix the languages to make a sentence to answer his teachers who required him to speak Persian. My son had watched only Turkish satellite channels so he had no exposure to Persian at all. So with my younger child, I have not allowed him to watch any channels but Pooya cartoon network. When children start the first grade this helps a lot.

The parent (P6) is a mother of two sons and a homemaker. Her account of her language choice with her children depicts the constraining force of monolingual educational policies on the parents' linguistic decisions at home. As noted above, although Article 15 of the Constitution allows the teaching of ethnic minority languages in the education system, Persian has remained the only medium and subject of instruction. ${ }^{1}$ Thus, the students will have to know Persian very well or they would face failure; in May's words, they have to sink or swim (May 2012:172). Having "watched only Turkish satellite channels"-broadcast from Turkey — and "not exposed to Persian" adequately, her older son "had many problems at school". The "problems' originate from the fact that "schools require the child to speak Persian" and they do not approve of non-Persian languages and language mixing. The lack of supportive bilingual programs for Azerbaijani speaking children in the education system encourages the parents at home to exercise their agency to 'ease their children's integration into school' (Spolsky 2011:153). Based on their evaluation of past experience with their older child's language development, they decide to rely on Persian channels, particularly Pooya, which is a cartoon network broadcast nationwide in Persian. As this parent (P6) believes, exposing the child to Persian cartoons at home will help the children "when they start the first grade". Similar kinds of language management at home under the influence of the availability and accessibility of certain media and their impact on the child's language development were also reported by other parents. 
P11: My children want to learn Persian more than Azerbaijani because he does not understand Persian cartoons he wants to understand them.

P7: We've been watching Pooya after my child's birth. He watches 2-3 hours a day. After he goes to sleep, I watch Turkish channels.

The parents' comments clearly show how the Pooya cartoon network has become a useful tool for the families in introducing and promoting Persian. Broadcasting interesting foreign cartoons and children's programs professionally dubbed into Persian creates a push factor encouraging the children to "learn Persian more than Azerbaijani" so that "they can understand Persian cartoons". Making a conscious decision to use the Pooya cartoon network at home as a tool to teach children Persian, that is, exercising agency, is particularly clear in P7's comment. "After the child was born", they "have been watching Pooya 2-3 hours a day". Interestingly enough, the parent switches to Turkish channels "after the child goes to sleep".

When asked why they do not encourage the children to watch Sahand TV, the provincial minority channel for Azerbaijanis in Tabriz, the parents provided two answers. The first answer was that even if the children want to watch Sahand TV, they would be exposed to Persian because the children's programs are in Persian.

P7: Sahand TV's cartoons are in Persian and it is very limited.

The second answer was about the quality of the programs on Sahand TV. One parent (P4) was in fact very particular about the issue of quality.

P4: Are the presenters of Sahand TV the same as the presenters of Persian channels? Have you seen the presenter doing weather forecast on Sahand TV? His suit is not even fit. The people who watch the channel will have negative feelings of it. If we want to encourage using the language, it must be appealing.

Posing a rhetorical question, "are the presenters of Sahand TV the same as the presenters of Persian channels?" the parent (P4), who holds a PhD degree in chemical engineering, complains about the quality of Sahand TV, even the way people are dressed on the channel. She concludes that "the people who watch the channel will have negative feelings of it". Because Sahand TV is budgeted and run by the Islamic Republic of Iran Broadcasting (IRIB), it can be considered a TV channel 'for the minority' rather than 'by the minority' (Caspi \& Elias 2011). Thus, its staff, budget, and agenda, for example, having half of the programs in Persian, seem to be determined by the central government. Furthermore, in its current condition, the channel is not 'institutionally complete and qualitatively competitive' (Moring 2007:29). A low level of institutional completeness, that is, the inability to produce high-quality and attractive programs for people, especially children and teenagers, in the minority language (see Cheval 1992:193), has led to negative attitudes, persuading the people to turn to predominantly Persian national channels or Turkish satellite channels - broadcast from Turkey (see also Mirvahedi \& Nasjian 2010; Mirvahedi 2012; Zeinalabedini 2014).

In short, the lack of supportive, high quality, and effective institutional support for Azerbaijanis, especially in the form of educational policies and access to the 
media, has created constraining forces outside the home influencing the parents' agency at home. Through reflexive deliberation, parents weigh a variety of individual and/or collective aspirations, decisions, and choices against the backdrop of structural possibilities and constraints, which ultimately inform their future courses of action (Archer 2007). The result is a family language policy that promotes Persian at home.

\section{Historical stigmatization of Azerbaijani-speaking Turks}

The third theme that emerged from the data reflects the historicity of social phenomena (Blommaert 2005; Hult 2017b). While the parent's (P5) account of her linguistic ideologies and practices at home suggests she contests existing structural forces to speak Persian at home, she refers to the historical stigmatization of the Azerbaijani, which in addition to the educational policies shapes the parents' linguistic ideologies and practices. In doing this, she implies that such a historical background is one reason for the Azerbaijani parents' language choice at home.

P5: I have a 9-year old son. I've always spoken Azerbaijani with him. They said he would have trouble in school. But I do not see a need to speak Persian with him given that I speak Azerbaijani all day. I would like him to learn Persian. It is better for him to gain mastery of the second language but I wouldn't speak Persian with him because of schools. He learns Persian from his friends. But after he leaves school, I do not allow him to use Persian in the home. At school, he has to learn Persian. Over time, he will learn it. Even with accent, I am ok with his speaking Persian with Azerbaijani accent. If we appreciate our own language, no one will ridicule it. Some years ago, they would say turk-e-khar ('donkey Turk') but that has reduced now. I think we must speak Azerbaijani with our children. If we do that he/she will do the same and the language will be maintained. I'm not saying that we do not learn Persian, we have to know it. But if we speak our mother tongue the children will know that their mother tongue is Azerbaijani.

This excerpt clearly shows how parents juggle different individual and public discourses. On the one hand, referring to the prevalence of a societal discourse about the importance of Persian among the families, "they said he would have trouble in school", the parent (P5) agrees that "it is better for him [her son] to gain mastery of the second language". However, on the other hand, she contests the idea that families should speak Persian in the home. Thus, believing that schools provide a space for her son to learn Persian-"at school, he learns Persian from his friends"- - she concludes that she does "not see a need to speak Persian with him" at home. Having developed such a language ideology, her language management at home is shaped in such a way that it does "not allow the child to use Persian at home after he leaves school". The parent's account of her language ideology, practice, and management suggests that parents should not be viewed as 'cultural dopes' or 'bearers of a mode of reproduction' (Giddens 1979:71). Rather, depending on how they interpret the structural forces, their agency is shaped in a way that either reproduces the current status quo or transforms it. Although the majority of families may interpret the monolingual Persian schools as a constraining force with which they need to comply at home, some find schools a space for learning Persian, rejecting the idea of introducing it in the home. 
Besides setting an example of how parents may contest structural forces, this mother's account links the prevalence of 'Persian as a home language' discourse among families to the historical stigmatization of Azerbaijani in the country. Clearly mentioning that "some years ago, they [speakers of other languages] would say turk-e-khar ('donkey Turk')", she expresses that "she is ok" if "her son learns Persian at school over time", and "speaks it with Azerbaijani accent". Supporting active use of Azerbaijani in the family, she argues that if all Azerbaijani-speaking communities "appreciate [their] own language, no one will ridicule it". And this is how "the language will be maintained". This extract of the interview illustrates how agency is 'a temporally embedded process of social engagement', which is 'informed by the past' but also 'oriented toward the future (as a 'projective' capacity to imagine alternative possibilities) and toward the present (as a 'practical-evaluative' capacity to contextualize past habits and future projects within the contingencies of the moment)' (Emirbayer \& Mische 1998:962). Informed by a past of stigmatization of Azerbaijani-accented Persian and having been subjected to insults such as "turk-e-khar ('donkey Turk')", parents evaluate their present practices, deciding to invest in Persian from early ages.

The issue of accent appears to be so important to families that they seem to aspire to raise their children as native Persian speakers. As one parent remarks, the "children should learn Persian well so that they are not distinguished among people" (P13). By being 'distinguished', parents refer to the fact that the child's speech should not reveal his/her ethnicity: "As soon as the child opens his/her mouth, it is obvious that he/she is a Turk" (P1). Thus, parents' investment in Persian from an early age is done as the families imagine an alternative possibility for their children in the future, that is, in a future society where their children will not be subject to insults and stigmatization. Although such parental aspirations for children are not surprising, the consequence for their mother tongue can be arguably negative in the long run, encouraging more and more families to use Persian at home at the cost of Azerbaijani.

\section{Limited resistance to the existing structure}

The following excerpts constituting the fourth theme illustrate what Archer refers to as 'agential elaboration' (Archer 1995:196), that is, as individuals constantly contribute to structural reproduction or transformation, they reconstitute themselves as well. It is through such a cyclical process that individuals' actions contribute (along with those of many others) to subtle or radical reproduction (morphostasis) or transformation (morphogenesis) of the pre-existing structures (Archer 1995:154-61). The following illustrates how parents have embraced the existing ideologies that have reconstituted them as agents who contribute to sustaining the hegemony of Persian.

Not having received any formal education in Azerbaijani (except for one year in 1945), parents' reading and writing skills have drastically declined over generations. Below, the parent (P1) describes the situation well. 
P1: My mastery of the Azerbaijani language is $60-65 \%$. Because firstly, we have learned the language orally/aurally; we have not learned its grammar. Secondly, Persian words have entered our language, and you see I'm constantly using Persian words. I can say we only use the verbs in Azerbaijani. So compared to reading and writing in Persian, I have difficulty reading and writing in Azerbaijani. Especially, a scientific text, for example, I can hardly read in Azerbaijani. We are used to reading such texts in Persian.

P7: Reading a page in Azerbaijani takes an hour.

Monolingual educational policies of the state and consequently the erasure of Azerbaijani from the education system have turned it into an oral/aural language. The parents thus "have not learned its grammar and they have difficulty reading and writing in Azerbaijani". Persian words have entered Azerbaijani and "using Persian words" while speaking Azerbaijani is noticeable. As the parent puts it (though it may sound exaggerated), they "only use verbs in Azerbaijani". It is under such circumstances that the parents rely on Persian for reading and writing in a variety of contexts (e.g. see Mirvahedi 2016 for the absence of Azerbaijani on the linguistic landscapes in Tabriz). Having been subjected to such 'monolingual reductionism' (Skutnabb-Kangas 1998:12), and 'marginalizing ideology' (Lotherington 2004:698) in the education system, Azerbaijani parents have been reconstituted as individuals who lack competence in reading and writing their own language and who use Persian words excessively when they speak Azerbaijani. As such people, they do not appear to be agents who would desire fundamental changes to transform the status quo.

P2: I do not see any necessity to enter Azerbaijani into the education system as a medium of instruction ... I would agree with having it as a subject.

P3: I personally agree with introducing Azerbaijani into the education system, but I think even if we do that, it won't be used in the country, because our national and official language is Persian. We know the language so there is no need to have it in the education system. But if we want to maintain the language, it will be better to have it as a subject. Even in that case, I think it won't have any use in the country. Only we will use it.

In response to the question of what potential changes the parents would welcome that might help with their language maintenance, they all desired introducing Azerbaijani in the education system, though only as a subject of instruction and not as a medium of instruction. The parents "do not see any necessity to enter Azerbaijani into the education system as a medium of instruction" (P2) because they believe the "national and official language is Persian" and "Azerbaijani will not have any use in the country" (P3). Although the parents acknowledge that having Azerbaijani at school as a subject can contribute to its better maintenance, they seem to be unaware of fully fledged bilingual policies that could be implemented under Article 15 of the Constitution to better support minority languages. What can be conceived of is the continuing reproduction of the current status quo, that is, increasingly reinforcing the hegemony of Persian by investing in it at home and encouraging and contributing to language shift from Azerbaijani to Persian in the families. 
As a point of departure in this article, I took the premise that language ideologies, practices, and management in a family do not take place in a social vacuum; rather, they interact with the sociopolitical, historical, and economic realities in which families find themselves. What this suggests is the fact that individuals' capacity to act in the family, rather than being their free will and intention acting from a rational position, is emergent in and from larger social, political, and cultural structures (Ahearn 2001; Sicoli 2011). I have argued that social structure and its impact on family members' decisions and practices should not be then treated as merely 'background information' (Williams 1992:66), but, rather, be systematically incorporated in the analysis. Illustrated by the case of Azerbaijanis in Iran, I have shown that one way to do so is to ground FLP research in realist social theory, which views the social world as ontologically 'stratified', thus giving both agency and structure real emergent properties that are irreducible to each other; this makes it possible to analyze them with no conflation of any sort (Archer 1995:67, 75). Sociological realism then enables us to include and integrate synchronic as well as diachronic, situated as well as historical, and structural as well as agentive dimensions in family language policy analysis.

Historically, since the late nineteenth century, speakers of minority languages in Iran have lived in a state where Persian nationalism has functioned as the dominant ideology (Soleimani \& Muhammadpour 2019). The ideology was constitutionalized in the 1905 Constitutional Revolution, making Persian the only official language of the country (Mirvahedi 2019), which was later taken to repress non-Persian languages and identities in favor of a 'one country, one nation, one language' policy during the Pahlavi dynasty (Soleimani \& Muhammadpour 2019). Although minority languages, labeled regional and tribal languages, were included in the Constitution after the 1979 Islamic Revolution to allow them to appear in the education system and media, Persian has continued to be the sole official and institutional language in the country. As a result of such a 'discursive ripple effect' (Hult 2010:19) as well as the material realities families encounter on a daily basis (e.g. Persian-medium schools and very limited access to Azerbaijani educational material), speakers of minority languages have come to be well aware of the fact that a lack of knowledge of Persian would deprive them of their right to participate in academic institutions, the labor market, and ultimately socioeconomic mobility.

We have observed above that the parents constantly refer to the official status of Persian and its pervasive use across the country, ultimately feeling the necessity to gain mastery in the language to guarantee higher social mobility. Parents thus do their best to raise children who speak Persian as 'perfectly' as possible given that they would not want their children to speak accented Persian as it may reveal their stigmatized ethnic identity and be used to penalize them in one way or another. In achieving their goal, parents 'take advantage' of the dominance of Persian on the broadcast media, children's programs in particular, to expose their children to Persian programs to encourage them to learn Persian before school 
age. This suggests that the majority of Azerbaijani parents actively mobilize the discourse of Persian as the only official language of the country in the home, reproducing its hegemony over Azerbaijani (see Fairclough, Jessop, \& Sayer 2004; Bouchard 2017 for discourse in sociological realism).

What sociological realism makes possible to observe and explain in FLP scholarship is how the same circumstances could be interpreted differently by different members of the community, bringing about a distinct behavior. The analysis has shown that while some parents find Persian-medium schools a constraining factor making them introduce Persian to their children at home at a very young age, others view this as an opportunity to delegate the responsibility of teaching Persian to schools, and thus save the home for speaking and maintaining Azerbaijani. This observation indicates that, as Sayer (1992) argues, social structures do not endure automatically unless the people reproduce them. However, people do not always reproduce them automatically and intentionally. Rather, people are under the influence of the interpretations that elements of the structure attribute to their social markers such as race/ethnicity, nationality, gender, religion, and social status (Adams 2015). This suggests that the ideological component of FLP should not then include only ideologies about languages, but also ideologies about sociopolitical, historical, and economic structures in which families find themselves. It is the parents' sense-making of the structures-language regime being one of them - that constitute the ideological component of FLP, which in turn informs the families' language ideologies and practices.

In short, I have shown that because the power of parents as policy actors is contingent upon societal factors of a structuring nature, a balanced account of structure and agency will offer a full grasp of language ideologies, practices, and management at familial level (see Johnson \& Ricento 2013 and Van Mensel 2016 for a discussion of agency and structure in language policy research). Adopting realist social theory to explore the parents' agency and social structures emphasizes that the growing body of FLP research needs to view FLP as a multilayered construct, an ensemble of family members' sense-making of a variety of social structures. This suggests that FLP research cannot and should not consider home and family a private space; rather, home is a site where public and private spheres meet. This will illuminate how, in Gafaranga's (2010:266, emphasis in original) words, 'The macro-sociological order ocCASIONS the conversational order' at home, which will have important implications for the vitality of minority languages.

\section{N O T E}

${ }^{1}$ Arabic and English are taught as foreign languages.

\section{R E F E R E N C E S}

Adams, C. Jama (2015). Structure and agency: Africana immigrants in China. The Journal of Pan African Studies 7(10):85-108.

Ahearn, Laura M. (2001). Language and agency. Annual Review of Anthropology 30:109-37. 


\section{EXAMINING FAMILY LANGUAGE POLICY}

Archer, Margaret S. (1995). Realist social theory: The morphogenetic approach. Cambridge: Cambridge University Press.

(2000). Being human: The problem of agency. Cambridge: Cambridge University Press.

(2003). Structure, agency and the internal conversation. Cambridge: Cambridge University Press.

(2007). Making our way through the world: Human reflexivity and social mobility. Cambridge:

Cambridge University Press.

(2012). The reflexive imperative in late modernity. Cambridge: Cambridge University Press.

Asgharzadeh, Alireza (2007). Iran and the challenge of diversity: Islamic fundamentalism, Aryanist racism, and democratic struggles. New York: Palgrave Macmillan.

Bani-Shoraka, Helena (2009). Cross-generational bilingual strategies among Azerbaijanis in Tehran. International Journal of Sociology of Language 198:105-27.

Blommaert, Jan (2005). Discourse: A critical analysis. Cambridge: Cambridge University Press. (2019). Foreword. In Haque, 1-5.

Bouchard, Jeremie (2017). Ideology, agency, and intercultural communicative competence: A stratified look into EFL education in Japan. Singapore: Springer.

\& Gregory Paul Glasgow (eds.) (2018). Agency in language policy and planning: Critical inquires. New York: Routledge.

Braun, Virginia, \& Victoria Clarke (2006). Using thematic analysis in psychology. Qualitative Research in Psychology 3:77-101.

Canagarajah, A. Suresh (2008). Language shift and the family: Questions from the Sri Lankan Tamil diaspora. Journal of Sociolinguistics 12(2):143-76.

Carter, Bob, \& Alison Sealey (2000). Language, structure and agency: What can realist social theory offer to sociolinguistics? Journal of Sociolinguistics 4(1):3-20.

Caspi, Dan, \& Nelly Elias (2011). Don't patronize me: Media-by and media-for minorities. Ethnic and Racial Studies 34(1):62-82.

Charmaz, Kathy (2006). Constructing grounded theory: A practical guide through qualitative analysis. London: SAGE.

Cheval, Jean-Jacques (1992). Local radio and regional languages in southwestern France. In Stephen Harold Riggins (ed.), Ethnic minority media: An international perspective, 165-95. New York: SAGE.

Curdt-Christiansen, Xiao Lan (2013). Family language policy: Sociopolitical reality versus linguistic continuity. Language Policy 12:1-6. doi: 10.1007/s10993-012-9269-0.

De Houwer, Annick (1999). Environmental factors in early bilingual development: The role of parental beliefs and attitudes. In Guus Extra \& Ludo Verhoeven (eds.), Bilingualism and migration, 75-95. Berlin: Mouton de Gruyter.

Edwards, Jane (2016). Socially-critical environmental education in primary classrooms: The dance of structure and agency. New York: Springer.

Elder-Vass, Dave (2014). Debate: Seven ways to be a realist about language. Journal for the Theory of Social Behaviour 44(3):249-67. doi: 10.1111/jtsb.12040.

Emirbayer, Mustafa, \& Ann Mische (1998). What is agency? American Journal of Sociology 103 (4):962-1023.

Fairclough, Norman; Bob Jessop; \& Andrew Sayer (2004). Critical realism and semiosis. In Jonathan Joseph \& John Michael Roberts (eds.), Realism discourse and deconstruction, 23-42. London: Routledge.

Fishman, Joshua A. (1972). Societal bilingualism: Stable and transitional. In Anwar S. Dil (ed.), Language in socioculctural change: Essays by Joshua A. Fishman, 135-52. Stanford, CA: Stanford University Press. - (2006). Language policy and language shift. In Thomas Ricento (ed.), An introduction to language policy: Theory and method, 311-28. New York: Blackwell.

(2013). Language maintenance, language shift, and reversing language shift. In Tej K. Bhatia \& William C. Ritchie (eds.), The handbook of bilingualism and multilingualism, 2nd edn., 466-94. Malden, MA: Blackwell.

Fogle, Lyn W., \& Kendall A. King (2017). Bi- and multilingual family language socialization. In Patricia A. Duff \& Stephen May (eds.), Language socialization, 61-77. New York: Springer. 


\section{SEYED HADI MIRVAHEDI}

Gafaranga, Joseph (2010). Medium request: Talking language shift into being. Language in Society 39(2):241-70.

Giddens, Anthony (1979). Central problems in social theory: Action, structure and contradiction in social analysis. London: Palgrave Macmillan.

Giles, Howard; Richard Y. Bourhis; \& Donald M. Taylor (1977). Towards a theory of language in ethnic group relations. In Howard Giles (ed.), Language, ethnicity and intergroup relations, 307-48. London: Academic Press.

Haddadian-Moghaddam, Esmaeil, \& Reine Meylaerts (2015). What about translation? Beyond 'persianization' as the language policy in Iran. Iranian Studies 48(6):851-70. doi: 10.1080/00210862.2014.913437.

Hadley, Gregory (2017). Grounded theory in applied linguistics research: A practical guide. London: Routledge.

Haque, Shahzaman (ed.) (2019). Family language policy: Dynamics in language transmission under a migratory context. Munich: LINCOM GmbH.

Hassanpour, Amir; Jaffer Sheyholislami; \& Tove Skutnabb-Kangas (2012). Kurdish: Linguicide, resistance and hope. International Journal of the Sociology of Language 217:1-18.

Hawes, Thomas, \& Seyed Hadi Mirvahedi (2013). Language attrition and loss of identity: Azeri-Farsi codeswitching in Tabriz Iran. In Kelechukwu U. Ihemere (ed.), Language contact: A multidimensional perspective, 248-65. Cambridge: Cambridge Scholars.

Hayati, Abdolmajid M., \& Amir Mashhadi (2010). Language planning and language-in-education policy in Iran. Language Problems \& Language Planning 34(1):24-42. doi: 10.1075/1plp.34.1.02hay.

Hays, Sharon (1994). Structure and agency and the sticky problem of culture. Sociological Theory 12(1):57-72.

Hult, Francis M. (2010). Analysis of language policy discourses across the scales of space and time. International Journal of the Sociology of Language 202:7-24.

(2017a). Discursive approaches to policy. In Stanton Wortham, Deoksoon Kim, \& Stephen May (eds.), Discourse and education, 3rd edn., 111-21. New York: Springer.

(2017b). Nexus analysis as scalar ethnography for educational linguistics. In Marilyn Martin-Jones \& Deirdre Martin (eds.), Researching multilingualism: Critical and ethnographic perspectives, 89-104. New York: Routledge.

Johnson, David Cassels (2013). Language policy. Basingstoke: Palgrave Macmillan.

— \& Thomas Ricento (2013). Conceptual and theoretical perspectives in language planning and policy: Situating the ethnography of language policy. International Journal of Sociology of Language 219:7-21.

Karimzad, Farzad (2018). Language ideologies and the politics of language: The case of Azerbaijanis in Iran. In Madina Djuraeva \& Francois Victor Tochon (eds.), Language policy or the politics of language: Reimagining the role of language in a neoliberal society, 53-75. Blue Mounds, WI: Deep University Press.

Kheirkhah, Mina, \& Asta Cekaite (2015). Language maintenance in a multilingual family: Informal heritage language lessons in parent-child interactions. Multilingua 34(3):319-46.

- \& - (2018). Siblings as language socialization agents in bilingual families. International Multilingual Research Journal 12(4):255-72. doi: 10.1080/19313152.2016.1273738.

Lane, Pia (2015). Minority language standardisation and the role of users. Language Policy 14:263-83. doi: 10.1007/s10993-014-9342-y.

Lanza, Elizabeth (1998). Raising children bilingually in Norway. International Journal of Sociology of Language 133:73-88.

(2007). Multilingualism and the family. In Peter Auer \& Li Wei (eds.), Handbook of multilingualism and multilingual communication, 45-67. Berlin: De Gruyter.

Lotherington, Heather (2004). Bilingual education. In Alan Davies \& Catherine Elder (eds.), The handbook of applied linguistics, 695-718. Malden, MA: Blackwell.

May, Stephen (2012). Language and minority rights: Ethnicity, nationalism, and the politics of language. New York: Routledge. 


\section{EXAMINING FAMILY LANGUAGE POLICY}

Mirhosseini, Seyyed-Abdolhamid, \& Parisa Abazari (2016). 'My language is like my mother': Aspects of language attitudes in a bilingual Farsi-Azerbaijani context in Iran. Open Linguistics 2:373-85.

Mirshahidi, Shahriar (2017). I find you attractive but I don't trust you: The case of language attitudes in Iran. Journal of Multilingual and Multicultural Development 38(2):146-59.

Mirvahedi, Seyed Hadi (2012). The role of satellite channels in language shift/maintenance: The case of Tabriz, Iran. In G. H. Lewis \& N. Ostler (Eds.) Proceedings of FEL XIV (pp. 36-41). Auckland, New Zealand: Foundation for Endangered Languages.

(2016). Linguistic landscaping in Tabriz, Iran: A discursive transformation of a bilingual space into a monolingual place. International Journal of the Sociology of Language 242:195-216.

(2017). Exploring family language policy among Azerbaijani-speaking families in the City of Tabriz. In John Macalister \& Seyed Hadi Mirvahedi (eds.), Family language policy in a multilingual world: Challenges, opportunities, and consequences, 92-112. New York: Routledge.

(2019). Nationalism, modernity, and the issue of linguistic diversity in Iran In Seyed Hadi Mirvahedi (ed.), The sociolinguistics of Iran's languages at home and abroad: The case of Persian, Azerbaijani, and Kurdish, 1-21. Cham: Palgrave.

- \& John Macalister (2017). Home as a confluence of discourses in multilingual linguistic ecologies. In John Macalister \& Seyed Hadi Mirvahedi (eds.), Family language policy in a multilingual world: Challenges, opportunities, and consequences, 268-86. New York: Routledge.

- \& Nima Nasjian (2010). Is Azeri going to live or leave? A critical study of institutional supports available to Azeri in Tabriz, Iran. Paper presented at the Reversing Language Shift: How to Reawaken a Language Tradition, University of Wales.

Moring, Tom (2007). Functional completeness in minority language media. In Mike Cormack \& Niamh Hourigan (eds.), Minority language media: Concepts, critiques, and case studies, 17-33. Clevedon: Multilingual Matters.

Naghdipour, Bakhtiar (2014). Jokes in Iran (A sociolinguistic perspective). Folklore 50:105-20. doi: 10.7592/FEJF2014.59.naghdipour.

Paul, Ludwig (1999). Iranian nation and Iranian-Islamic revolutionary ideology. Die Welt des Islams 39 (2):183-217.

Phillipson, Robert (1988). Linguicism: Structures and ideologies in linguistic imperialism. In Tove Skutnabb-Kangas \& Jim Cummins (eds.), Minority education: From shame to struggle?, 339-58. Clevedon: Multilingual Matters.

Rezaei, Saeed; Ashkan Latifi; \& Arash Nematzadeh (2017). Attitude towards Azeri language in Iran: A largescale survey research. Journal of Multilingual and Multicultural Development. doi: $10.1080 / 01434632.2017 .1342652$.

Riaux, Gilles (2008). The formative years of Azerbaijani nationalism in post-revolutionary Iran. Central Asian Survey 27(1):45-58.

Sayer, Andrew (1992). Method in social science: A realist approach. 2nd edn. London: Routledge.

Sealey, Alison (2007). Linguistic ethnography in realist perspective. Journal of Sociolinguistics 11 (5):641-60.

- \& Bob Carter (2004). Applied linguistics as social science. London: Continuum.

Sepehri, Mohammad Bagher (2010). Local radio audiences in Iran: An analysis of Ardebilian people's trust in and satisfaction with 'Sabalan' radio. Journal of Radio \& Audio Media 17(2):236-50.

Sewell, William H. (1992). A theory of structure: Duality, agency, and transformation. American Journal of Sociology 98(1):1-29.

Shaffer, Brenda (2002). Borders and brethren: Iran and the challenge of Azerbaijani identity. Cambridge, MA: The MIT Press.

Sheyholislami, Jaffer (2012). Kurdish in Iran: A case of restricted and controlled tolerance. International Journal of the Sociology of Language 217:19-47.

Shohamy, Elana (2006). Language policy: Hidden agendas and new approaches. London: Routledge. 


\section{SEYED HADI MIR VAHEDI}

Sicoli, Mark A. (2011). Agency and ideology in language shift and language maintenance. In Tania Grandillo \& Heidi A. Orcutt-Gachiri (eds.), Ethnographic contributions to the study of endangered languages, 61-176. Tucson: The University of Arizona Press.

Skerrett, Delaney Michael (2016). Moving the field forward: A micro-meso-macro model for critical language planning. The case of Estonia. Current Issues in Language Planning 17(1):106-30.

Skutnabb-Kangas, Tove (1998). Human rights and language wrongs: A future for diversity? Language Sciences 20(1):5-27.

Smith-Christmas, Cassie (2016). Family language policy: Maintaining an endangered language in the home. Basingstoke: Palgrave Macmillan.

Soleimani, Kamal, \& Ahmad Muhammadpour (2019). Can non-Persians speak? The sovereign's narration of 'Iranian identity'. Ethnicities 19(5):1-23. doi: 10.1177/1468796819853059.

Spolsky, Bernard (2004). Language policy. Cambridge: Cambridge University Press.

(2009). Language management. Cambridge: Cambridge University Press.

(2011). Language and society. In Peter K. Austin \& Julia Sallabank (eds.), The Cambridge handbook of endangered languages, 141-56. Cambridge: Cambridge University Press.

Spooner, Brian (2012). Persian, Farsi, Dari, Tajiki: Language names and language policies. In Harold F. Schiffman (ed.), Language policy and language conflict in Afghanistan and its neighbors: The changing politics of language choice, 89-117. Leiden: Brill.

Tohidi, Nayereh (2009). Ethnicity and religious Minority politics in Iran. In Ali Gheissari (ed.), Contemporary Iran: Economy, society, politics, 299-323. Oxford: Oxford University Press.

Tollefson, James W. (1991). Planning language, planning inequality: Language policy in the community. London: Longman.

(2006). Critical theory in language policy. In Thomas Ricento (ed.), An introduction to language policy: Theory and method, 42-59. New York: Blackwell.

Williams, Glyn (1992). Sociolinguistics: A sociological critique. London: Routledge.

Van Mensel, Luk (2016). Children and choices: The effect of macro language policy on the individual agency of transnational parents in Brussels. Language Policy 15(4):547-60. doi: 10.1007/s10993-015-9391-x.

(2018). 'Quiere koffie?' The multilingual familylect of transcultural families. International Journal of Multilingualism 15(3):233-48. doi: 10.1080/14790718.2018.1477096.

Willmott, Robert (2002). Education policy and realist social theory: Primary teachers, child-centred philosophy and the new managerialism. London: Routledge.

Zeinalabedini, Asefeh (2014). The people's attitude towards the language use in the local media broadcast: A case study of Azerbaijani language in Tabriz. Khazar Journal of Humanities and Social Sciences 17(4):5-28.

(Received 20 November 2018; revision received 16 October 2019; accepted 17 December 2019; final revision received 17 December 2019)

Address for correspondence:

Seyed Hadi Mirvahedi

Center for Multilingualism in Society Across the Lifespan, University of Oslo,

Norway 639798

s_h_mirvahedi@yahoo.com 